fors

Journal of Engineering Science and Technology Review 3 (1) (2010) 116-122

Research Article
JOURNAL OF

Engineering Science and

Technology Review

www.jestr.org

\title{
Power Prediction Model for Turning EN-31 Steel Using Response Surface Methodology
}

\author{
L. B. Abhang* and M. Hameedullah
}

Mechanical Engineering Department, Aligarh Muslim University, Aligarh, India.

Received 28 January 2010; Revised 17 March 2010; Accepted 25 May 2010

\begin{abstract}
Power consumption in turning EN-31 steel (a material that is most extensively used in automotive industry) with tungsten carbide tool under different cutting conditions was experimentally investigated. The experimental runs were planned according to $24+8$ added centre point factorial design of experiments, replicated thrice. The data collected was statistically analyzed using Analysis of Variance technique and first order and second order power consumption prediction models were developed by using response surface methodology (RSM). It is concluded that second-order model is more accurate than the first-order model and fit well with the experimental data. The model can be used in the automotive industries for deciding the cutting parameters for minimum power consumption and hence maximum productivity.
\end{abstract}

Keywords: Power, Response Surface methodology, Matlab, Minitab, Metal cutting.

\section{Introduction}

Turning is a very important machining process in which a single point cutting tool removes unwanted material from the surface of a rotating cylindrical work piece. The cutting tool is fed linearly in a direction parallel to the axis of rotation. Turning is carried on lathe that provides the power to turn the work piece at a given rotational speed and feed to the cutting tool at specified rate and depth of cut. Therefore three cutting parameters namely cutting speed, feed rate and depth of cut need to be optimized in a turning operation. Turning operation is one of the most important operations used for machine elements construction in manufacturing industries i.e. aerospace, automotive and shipping. Turning produces three cutting force components as shown in fig.1a, (the main cutting force i.e. thrust force, $\left(\mathrm{F}_{\mathrm{Z}}\right)$, which acts in the cutting speed direction, feed force, $\left(\mathrm{F}_{\mathrm{X}}\right)$, which acts in the feed rate direction and the radial force, $\left(\mathrm{F}_{\mathrm{Y}}\right)$, which acts in radial direction and which is normal to the cutting speed). Out of three force components the cutting force (main force) constitutes about $70 \%$ to $80 \%$ of the total force ' $\mathrm{F}$ ' and is used to calculate the power ' $\mathrm{P}$ ' required to perform the machining operation $[1,2,3]$.

Power is the product of main cutting force and the cutting velocity and is a better criterion for design and selection of any machine tools. Power consumption may be used for monitoring the tool conditions. The objective of using response surface methodology (RSM) is not only to investigate the response over the entire factor space, but also to locate the region of intrest where

*E-mail address: abhanglb@yahoo.co.in

ISSN: 1791-2377 (C) 2010 Kavala Institute of Technology. All rights reserved. the response reaches its optimum or near optimal values [4].

It has long been recognized that, in order to optimize the economic performance of machining operations, reliable quantitative technological performance data and equations are required for the wide spectrum of machining operations, tools and work piece materials used in practice [4]. It has also been recognized that improving the technological performance measures such as the chip formation, forces, power, and tool life, improves the economic performance of machining operations as assessed by the time per component, cost per component or other suitable measures [5]. WUSM [6] first pioneered the use of R.S.M. in tool life testing. The number of experiments required to develop a surface response equation can be reduced markedly by using factorial design of experiments as compared to the traditional one variable at a time approach. Chou and Song [7] have investigated the effect of tool nose radius on finish hard turning with ceramic tools. In this study, surface finish and tool wear were studied at different metal cutting conditions. Results show that large tool nose radii not only give a finer surface finish, but also result in considerable tool wear compared to small nose radius tools. Specific cutting energy also increases slightly with tool nose radius. Larger nose radius tools generate shallower white layers when cutting with worn tools. For new tools, small tool nose radius results in larger uncut chip thickness, and thus, induces deeper white layers. However effective rake angle has been kept constant in the study reported by Chou et al [7]. In these studies, only one parameter of the tool geometry has been studied, whereas more than one parameter is found to 
be significant and they may also have interaction effect on the response parameters.

Modeling and optimization are necessary for the control of the hard turning process to achieve improved product quality, high productivity and low cost. Suresh et al [8] have developed a surface roughness prediction model for turning mild steel using a response surface methodology. Surface roughness prediction model has also been optimized by using genetic algorithms. Similarly surface roughness prediction models for dry and wet turning of EN-31 steel with tungsten carbide tool have been developed and reported by Abhang and Hameedullah [9]. Second degree model were found to be more significant than the first degree model. The interaction effects of response parameters were also found to be significant.

Anirban Bhattacharya et al [10] have investigated the effect of cutting parameters on surface finish and power consumption during high speed machining of AISI irons steel using Taguchi design and ANOVA. In this study, combined technique of orthogonal array and analysis of variance was employed to investigate the contribution and effect of cutting speed, feed rate and depth of cut (only three factors) on three surface roughness parameters and power consumption were studied at different metal cutting conditions. The results showed a significant effect of cutting speed on surface roughness and power consumption, while the other parameters have not substantially affected the response. Sood et al [11] studied the specific energy where the power of machining is one of the parameter affecting the specific energy. Noodin et al [15] studied the application of response surface methodology in describing the performance of coated carbide tools when turning AISI1045 steel. The factors investigated were cutting speed, feed and side cutting edge angle. The response variables were surface finish and tangential force. ANOVA revealed that feed is the most significant factor influencing the response variables investigated. There have been plenty of recent applications of Taguchi techniques to materials processing for process optimization [16-17]. Statistical methods and Taguchi's technique were used for investigating machinability and optimizing power consumption [16]. Faleh et al [17] have reported that the power consumption is one of the most important parameters for online monitoring of tool conditions [17]. The study revealed that when cutting fluid is used, cryogenic environment is the most significant factor in minimizing power consumption followed by cutting speed and depth of cut [17]. The effects of feed rate and tool nose radius were found to be insignificant compared to other factors. Lin [18] has formulated the experimental results of surface roughness and cutting forces by regression analysis, and modeled the effects of them in his study using S5SC steel. Similar investigations have been reported by Risbood [19].

In the present work experimental investigations were conducted by turning EN-31 steel with tungsten carbide tool at different conditions of cutting speed, feed rate, depth of cut and tool nose radius. The cutting forces were measured and power consumption calculated. An attempt has been made to develop the first order and second order power prediction models with respect to various combinations of design variables (cutting speed, feed rate, depth of cut and tool nose radius) by response surface methodology with the factorial design of experiments and analysis of variance (ANOVA) applied to the uncoded data.

\section{Power Model}

The equation for the power is:

$\mathrm{P}=\mathrm{F}_{\mathrm{c}} * \mathrm{~V}$

Where $\mathrm{P}$ is the power in watt, $\mathrm{V}$ is the cutting speed in $\mathrm{m} /$ min and $F_{c}$ is the main cutting force in N. The power is dissipated mainly in the shear zone (due to the energy required to shear the material) and on the rake face of the tool (due to tool-chip interface friction). The sharpness of the tool tip also influences forces and power. Because it rubs against the machined surface and makes the deformation zone ahead of the tool larger the worn out tools require higher forces and power.

The proposed relationship between the machining responses (power) and machining independent variables can be represented in linear form:

Therefore,

Power $=a^{*}($ cutting speed $)+b^{*}($ feed rate $)+$

$+\mathrm{C}^{*}($ depth of cut $)+\mathrm{d}^{*}($ tool nose radius $)+\mathrm{e}$

Where, power is in watt (w) a, b, c, d and e are the constants. Eq. (2) can be written in the following form.

Therefore

$\mathrm{Y}=\varnothing(\mathrm{v}, \mathrm{f}, \mathrm{d}, \mathrm{r})+\varepsilon$

$Y=\beta_{0} x_{0}+\beta_{1} x_{1}+\beta_{2} x_{2}+\beta_{3} x_{2}+\beta_{3} x_{3}+\beta_{4} x_{4}$

Where, $\mathrm{Y}$ is the power, $\mathrm{X}_{0}=1$ (dummy variables), $\mathrm{X}_{1}=$ cutting speed, $X_{2}=$ feed rate, $X_{3}=$ depth of cut and $X_{4}=$ tool nose radius, $\beta_{0}=\mathrm{C}$ and $\beta_{1}, \beta_{2}, \beta_{3}$ and $\beta_{4}$ are the model parameters.

The relationship between the metal cutting power and machining independent variables represented in the following equation. The equation is,

$\mathrm{P}=\mathrm{CV}^{\mathrm{a}} \mathrm{F}^{\mathrm{b}} \mathrm{D}^{\mathrm{c}} \mathrm{R}^{\mathrm{d}}$

Where $\mathrm{C}$ is constant, and $\mathrm{a}, \mathrm{b}, \mathrm{c}$ and $\mathrm{d}$ are the exponents. Eq. (5) can be represented in linear mathematical form as follows:

$\operatorname{Lnp}=\operatorname{lnc}+a \operatorname{lnv}+b \operatorname{lnf}+c \operatorname{lnd}+d \ln r$

The constants and exponents c, a, b, c and d can be determined by the method of least squares. The first order linear model developed from the equation can be represented as follows:

$\mathrm{Y}_{1}=\mathrm{Y}-\varepsilon=\mathrm{b}_{0} \mathrm{x}_{0}+\mathrm{b}_{1} \mathrm{x}_{1}+\mathrm{b}_{2} \mathrm{x}_{2}+\mathrm{b}_{3} \mathrm{x}_{3}+\mathrm{b}_{4} \mathrm{x}_{4}$

Where, $\mathrm{Y}_{1}$ is the estimated response based on first order equation, $\mathrm{Y}$ is the measured machining power through cutting force (main force) on a logarithmic scale, $\mathrm{X}_{0}=1$ is a dummy variable. $X_{1}, X_{2}, X_{3}$ and $X_{4}$ are logarithmic transformations of cutting speed, feed rate, depth of cut and tool nose radius, respectively, $\varepsilon$ is the experimental error; and b values are the estimates of corresponding parameters. If this model is not sufficient to represent the process, and then the second order model will be developed. 
The general second order model is developed below.

$$
\begin{aligned}
Y_{2}=Y-\varepsilon= & b_{0} x_{0}+b_{1} x_{1}+b_{2} x_{2}+b_{3} x_{3}+b_{4} x_{4}+b_{12} x_{1} x_{2}+ \\
& +b_{23} x_{2} x_{3}+b_{14} x_{1} x_{4}++b_{24} x_{2} x_{4}+b_{13} x_{1} x_{3}+ \\
& +b_{34} x_{3} x_{4}+b_{11} x_{1}{ }^{2}+b_{22} x_{2}{ }^{2}+b_{33} x_{3}{ }^{2}+b_{44} x_{4}{ }^{2}
\end{aligned}
$$

Where $\mathrm{Y}_{2}$ is the estimate response based on second order equation. The parameters $b_{0}, b_{1}, b_{2}, b_{3}, b_{4}, b_{12}, b_{23}$ and $b_{14}$, are to be calculated by the method of least squares

The basic formula is,

$$
\mathrm{b}=\left(\mathrm{X}^{\mathrm{T}} \cdot \mathrm{X}\right)^{-1} \cdot \mathrm{X}^{\mathrm{T}} \cdot \mathrm{Y}
$$

Where, the calculation matrix $X$ and the variance matrix $\left(X^{\mathrm{T}} \cdot \mathrm{X}\right)^{-1}$, Hence the $\mathrm{b}$ values can be determined by using eq. (9). The variables coded by taking into account the capacity and the limiting cutting conditions of the lathe machine. The coded values of variables to be used in eq. (7) were obtained from the following transforming equations.

$\mathrm{X}_{1}=\ln v-\ln 189 / \ln 189-\ln 39$,

$\mathrm{X}_{2}=\ln f-\ln 0.15 / \ln 0.15-\ln 0.06$

$\mathrm{X}_{3}=\operatorname{lnd}-\ln 0.6 / \ln 0.6-\ln 0.2$,

$\mathrm{X}_{4}=\ln r-\ln 1.2 / \ln 1.2-\ln 0.4$

Where $\mathrm{X}_{1}$ is coded value of cutting speed $(\mathrm{V}), \mathrm{X}_{2}$ is the coded value of feed rate $(F), X_{3}$ is the coded value of depth gent $(D)$ and $\mathrm{X}_{4}$ is the coded value of tool nose radius (R).

\section{Experimental Conditions}

The material used for the experiments is grade EN-31 steel, which is popularly used in automotive type applications, like axle, bearings, spindle and molding dies etc. Its chemical composition is given in table1.The workpiece is of $500 \mathrm{~mm}$ length and $50 \mathrm{~mm}$ in diameter. The lathe used for machining operations is HMT heavy duty lathe (LTM20) machine. The cutting tool holder used for turning operation is WIDAX SCLCR 12, T3 and diamond shape carbide inserts (CNMA 120404, CNMA 120408, CNMA 120412), $\left(\alpha_{0}=6^{0}, \gamma_{0}=-6^{0}, \lambda \mathrm{s}=-6^{0}, \mathrm{Kr}=95^{\circ}, \varepsilon_{\mathrm{r}}=80^{\circ}, \mathrm{r}=0.4,0.8\right.$ and $1.2 \mathrm{~mm})$. The levels of cutting conditions i.e. cutting speed, feed rate, depth of cut and tool nose radius are listed in table 2. To elaborate the plan of experiments the method of factorial design with eight aided centre points with coded design used as shown in

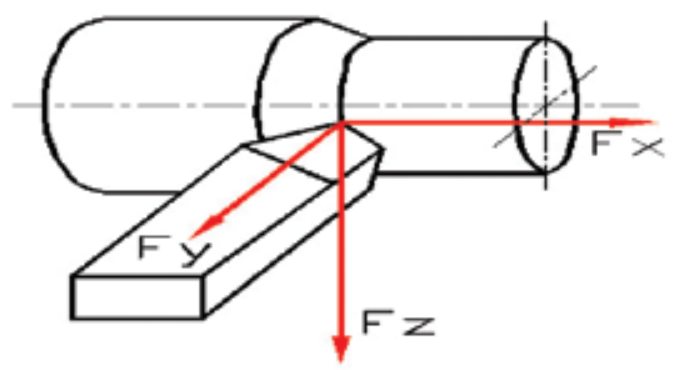

Figure 1a. Cutting forces acting on tool table 3 [12], [13]. Similarly table 4 shows the experimental cutting conditions together with the actual values of cutting parameters and measured cutting force with the calculated power using equation 1. On line measurement of cutting force is carried out using lathe tool dynamometer (strain gauge type three components lathe tool dynamometer as shown in figure $1 \mathrm{~b}$ and figure $1 \mathrm{c}$.

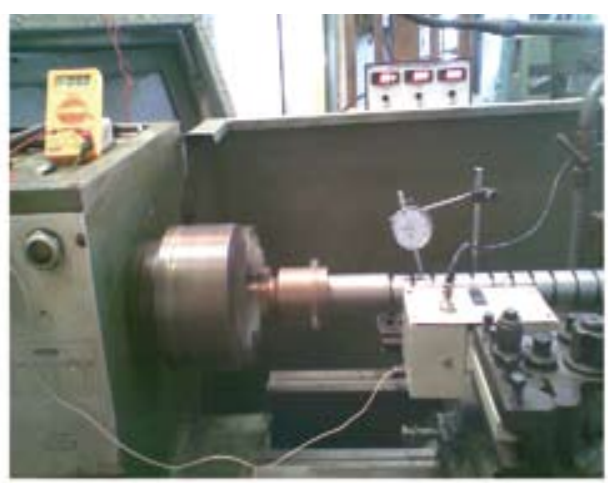

Figure 1b. Main cutting force experimental set-up

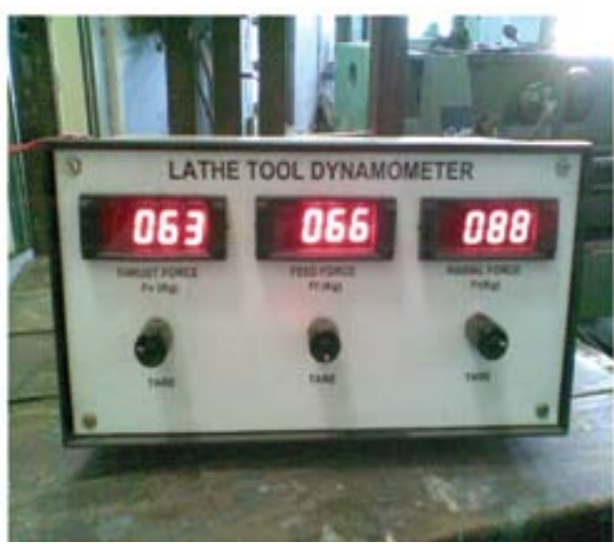

Figure 1c. Lathe tool dynamometer

Table 1. Chemical compositions of steel alloy (EN-31) Work

\begin{tabular}{|c|c|c|c|c|c|}
\hline Levels & $\begin{array}{c}\text { Speed } \\
\text { (m/min) }\end{array}$ & $\begin{array}{c}\text { Feed } \\
(\mathrm{mm} / \mathrm{rev})\end{array}$ & $\begin{array}{c}\text { Depth of } \\
\text { Cut } \\
\text { (mm) }\end{array}$ & $\begin{array}{c}\text { Nose } \\
\text { Radius } \\
(\mathrm{mm})\end{array}$ & code \\
\hline High & $189 \mathrm{~m} / \mathrm{min}$ & $\begin{array}{c}0.15 \mathrm{~mm} / \\
\text { rev. }\end{array}$ & $0.6 \mathrm{~mm}$ & $1.2 \mathrm{~mm}$ & +1 \\
\hline medium & $112 \mathrm{~m} / \mathrm{min}$ & $\begin{array}{c}0.10 \mathrm{~mm} / \\
\text { rev. }\end{array}$ & $0.4 \mathrm{~mm}$ & $0.8 \mathrm{~mm}$ & 0 \\
\hline Low & $039 \mathrm{~m} / \mathrm{min}$ & $\begin{array}{c}0.06 \mathrm{~mm} / \\
\text { rev. }\end{array}$ & $0.2 \mathrm{~mm}$ & $0.4 \mathrm{~mm}$ & -1 \\
\hline
\end{tabular}
piece.

\begin{tabular}{cccccccc}
\hline Composition & C & Si & Mn & Cr & Co & S & P \\
\hline \multirow{2}{*}{ Wt. \% } & $\begin{array}{r}0.95- \\
1.2\end{array}$ & $\begin{array}{r}0.10- \\
0.35\end{array}$ & $\begin{array}{c}0.30- \\
0.75\end{array}$ & $\begin{array}{r}1.0- \\
1.6\end{array}$ & 0.025 & 0.040 & 0.04 \\
\hline
\end{tabular}

Table 2. Levels of independent variables. 
Table 3. Design matrix.

\begin{tabular}{|c|c|c|c|c|c|}
\hline Exp. Run & $\mathbf{X}_{1}$ & $\mathbf{X}_{2}$ & $\mathbf{X}_{3}$ & $\mathbf{X}_{4}$ & Response Fz (N) \\
\hline 1 & -1 & -1 & -1 & -1 & 68.87 \\
\hline 2 & -1 & -1 & -1 & +1 & 76.82 \\
\hline 3 & -1 & -1 & +1 & -1 & 166.77 \\
\hline 4 & -1 & -1 & +1 & +1 & 186.58 \\
\hline 5 & -1 & +1 & -1 & -1 & 49.05 \\
\hline 6 & -1 & +1 & -1 & +1 & 157.15 \\
\hline 7 & -1 & +1 & +1 & -1 & 264.87 \\
\hline 8 & -1 & +1 & +1 & +1 & 323.93 \\
\hline 9 & +1 & -1 & -1 & -1 & 39.24 \\
\hline 10 & +1 & -1 & -1 & +1 & 97.39 \\
\hline 11 & +1 & -1 & +1 & -1 & 166.77 \\
\hline 12 & +1 & -1 & +1 & +1 & 209.23 \\
\hline 13 & +1 & +1 & -1 & -1 & 127.53 \\
\hline 14 & +1 & +1 & -1 & +1 & 143.53 \\
\hline 15 & +1 & +1 & +1 & -1 & 294.3 \\
\hline 16 & +1 & +1 & +1 & +1 & 329.98 \\
\hline 17 & 0 & 0 & 0 & 0 & 176.58 \\
\hline 18 & 0 & 0 & 0 & 0 & 186.39 \\
\hline 19 & 0 & 0 & 0 & 0 & 166.87 \\
\hline 20 & 0 & 0 & 0 & 0 & 147.16 \\
\hline 21 & 0 & 0 & 0 & 0 & 183.51 \\
\hline 22 & 0 & 0 & 0 & 0 & 157.12 \\
\hline 23 & 0 & 0 & 0 & 0 & 186.49 \\
\hline 24 & 0 & 0 & 0 & 0 & 177.48 \\
\hline
\end{tabular}

Table 4. Experiment conditions, Cutting force and calculated power using eq. (1).

\begin{tabular}{|c|c|c|c|c|c|c|c|c|}
\hline $\begin{array}{l}\text { Exp. } \\
\text { Run }\end{array}$ & $\begin{array}{c}\mathbf{V} \\
\mathbf{m} / \\
\mathrm{min}\end{array}$ & $\begin{array}{c}\mathrm{F} \\
\mathrm{mm} / \\
\mathrm{rev}\end{array}$ & $\begin{array}{c}\mathrm{D} \\
\mathbf{m m}\end{array}$ & $\begin{array}{c}\mathbf{R} \\
\mathbf{m m}\end{array}$ & $\begin{array}{c}\text { Response } \\
\text { Main } \\
\text { force (N) } \\
\text { Fc }\end{array}$ & $\begin{array}{c}\text { Power } \\
\text { calculated } \\
\text { (watt) }\end{array}$ & $\begin{array}{c}\text { Pre- } \\
\text { dicted. } \\
\text { Power } \\
\text { By first } \\
\text { order } \\
\text { model }\end{array}$ & $\begin{array}{c}\text { Predicted. } \\
\text { Power by } \\
\text { second or- } \\
\text { der mode }\end{array}$ \\
\hline 1 & 39 & 0.06 & 0.2 & 0.4 & 68.87 & 2685.93 & 1020.72 & 2777.22 \\
\hline 2 & 39 & 0.06 & 0.2 & 1.2 & 76.82 & 2995.98 & 2921.52 & 5350.564 \\
\hline 3 & 39 & 0.06 & 0.6 & .4 & 166.77 & 6504.03 & 6775.92 & 5171.516 \\
\hline 4 & 39 & 0.06 & 0.6 & 1.2 & 186.58 & 7276.62 & 8676.72 & 7744.86 \\
\hline 5 & 39 & 0.15 & 0.2 & 0.4 & 49.05 & 1912.95 & 2906.3 & 2497.77 \\
\hline 6 & 39 & 0.15 & 0.2 & 1.2 & 157.15 & 6128.85 & 5807.1 & 4165.57 \\
\hline 7 & 39 & 0.15 & 0.6 & 0.4 & 264.87 & 10329.93 & 9661.5 & 11999.51 \\
\hline 8 & 39 & 0.15 & 0.6 & 1.2 & 323.93 & 12633.27 & 11562.3 & 13667.31 \\
\hline 9 & 189 & 0.06 & 0.2 & 0.4 & 39.24 & 7416.36 & 7270.72 & 8360.22 \\
\hline 10 & 189 & 0.06 & 0.2 & 1.2 & 97.39 & 18406.71 & 29171.52 & 16177.56 \\
\hline 11 & 189 & 0.06 & 0.6 & 0.4 & 166.77 & 31519.53 & 33025.92 & 32954.52 \\
\hline 12 & 189 & 0.06 & 0.6 & 1.2 & 209.23 & 39355.47 & 34926.72 & 40771.86 \\
\hline 13 & 189 & 0.15 & 0.2 & 0.4 & 127.53 & 24103.17 & 30156.3 & 23322.27 \\
\hline 14 & 189 & 0.15 & 0.2 & 1.2 & 143.53 & 27127.17 & 32057.1 & 30234.07 \\
\hline 15 & 189 & 0.15 & 0.6 & 0.4 & 294.3 & 55622.7 & 35911.5 & 55024.01 \\
\hline 16 & 189 & 0.15 & 0.6 & 1.2 & 329.98 & 62366.22 & 37812.3 & 61935.81 \\
\hline 17 & 112 & 0.10 & 0.4 & 0.8 & 176.58 & 19776.96 & 18906.2 & 19206.82 \\
\hline 18 & 112 & 0.10 & 0.4 & 0.8 & 186.39 & 20875.68 & 18906.2 & 19206.82 \\
\hline 19 & 112 & 0.10 & 0.4 & 0.8 & 166.87 & 18689.44 & 18906.2 & 19206.82 \\
\hline 20 & 112 & 0.10 & 0.4 & 0.8 & 147.16 & 16481.92 & 18906.2 & 19206.82 \\
\hline 21 & 112 & 0.10 & 0.4 & 0.8 & 183.51 & 20553.12 & 18906.2 & 19206.82 \\
\hline 22 & 112 & 0.10 & 0.4 & 0.8 & 157.12 & 17597.44 & 18906.2 & 19206.82 \\
\hline 23 & 112 & 0.10 & 0.4 & 0.8 & 186.49 & 20886.88 & 18906.2 & 19206.82 \\
\hline 24 & 112 & 0.10 & 0.4 & 0.8 & 177.48 & 19877.76 & 18906.2 & 19206.82 \\
\hline
\end{tabular}

\section{Results and Discussions}

After completing the experiments an analysis of variance (ANOVA) was conducted to discern whether differences in cutting power between various runs were statistically significant. Table 5 presents ANOVAs results for experimental data generated during turning of alloy steel work piece. Value of "probability $>$ F" less than 0.0500 indicate model terms are significant. This is desirable as it indicates that the terms in the model have significant effect on the response. The power consumption equation of first order model is

$P=-11556+175 \mathrm{~V}+32062 \mathrm{~F}+14388 \mathrm{D}+2376 \mathrm{R}$

The table 5 shows the $95 \%$ confidence interval for the experiments. The analysis of variance of first order- model is shown in table 5. For the linear model, the p-value for lack of fit is 0.61 $(>0.05)$ is not significant with the lack of fit and the f-statistic is $0.75(>0.05)$. This implies that the model could fit and it is adequate. As well as the multiple regression coefficient of the first order model is $96.98 \%$, it is above $80 \%$. This result shows that feed rate has the most significant effect on the power, followed by depth of cut, tool nose radius and cutting speed. The equation shows that the power increases with increase in feed rate, depth of cut and tool nose radius. Eq.12 is utilized to calculate power counter at the selected depth of cut and tool nose radius. Figures $2 a-2 c$ show the cutting power counter with selected cutting parameters. The power reaches the highest value where the value of cutting speed, feed rate, depth of cut and tool nose radius at their maximum value (figure $2 \mathrm{c}$ ). The lowest power is obtained when all the factors value at their minimum value (figure $2 a$ ). From this counter plot, the safety zone of power can be selected for any experiment.

Table 5. Analysis of variance of first-order model (second block).

\begin{tabular}{cccccc}
\hline Source & DF & SS & MS & F-value & P-value \\
\hline Model & 4 & 516679645 & 129169911 & 42.99 & 0.000 \\
Residual error & 7 & 210323394 & 3004628 & - & - \\
Lack-fit & 4 & 10481121 & 2620280 & 0.75 & 0.621 \\
Pure error & 3 & 10551273 & 3517091 & - & - \\
Total & 11 & 537712038 & - & - & - \\
\hline
\end{tabular}

The second order model was postulated in obtaining the relationship between the cutting power and the machining independent variables. The model was based on the Box-Behnkn design method. The developed second order mathematical model is given in equation 13 .

$$
\begin{aligned}
\mathrm{P}= & 7305-122 * \mathrm{~V}-81591 * \mathrm{~F} 20290 * \mathrm{D}+2267 * \mathrm{R}+ \\
& +1129 * \mathrm{VF}+198120 * \mathrm{FD}+43.7 * \mathrm{VR}- \\
& -12577 * \mathrm{FR}+370 * \mathrm{VD}-691 * \mathrm{DR}
\end{aligned}
$$

The table 6 shows the $95 \%$ confidence interval for the experiments. The analysis of variance of second- order model as shown in tab. 6.For the second order model, the P-value for lack of fit is $0.159(>0.05)$ is not significant with the lack of fit and the F-statistic is $2.254(>0.05)$. This implies that the model could fit and it is adequate. The second order model is more precise than first order model, because the predicted result is much more accurate than the first order model. As well as the multiple regression coefficient 
of the second order model is higher than the first order model, i.e. $99.00 \%$ (0.99). The fit summery recommends that the (linear model) first order model as well as interaction model (second order) are statistically significant for analysis of cutting power.

Table 6. Analysis of variance of second- order model (Whole block).

\begin{tabular}{cccccc}
\hline Source & DF & SS & MS & F & P \\
\hline Model & 10 & 5365001231 & 536500123 & 130.36 & 0.000 \\
Residual error & 13 & 53501680 & 4115514 & - & - \\
Lack-fit & 6 & 35170430 & 5861738 & 2.254 & 0.159 \\
Pure error & 7 & 18331250 & 2618750 & - & - \\
Total & 23 & 5418502911 & - & - & - \\
\hline
\end{tabular}

Eq.13 is used to develop the counter plot as shown in figure $3 a$ to figure $3 c$. Figures $3 a-3 c$ shows that when the feed rate, cutting speed, depth of cut and tool nose radius are at their lowest value, the power consumption is the lowest and vice versa. From the counter plots we can see that the cutting conditions for the lowest power consumption are cutting speed $39 \mathrm{~m} / \mathrm{min}$, feed rate $0.06 \mathrm{~mm} /$ rev, depth of cut $0.2 \mathrm{~mm}$ and tool nose radius $0.4 \mathrm{~mm}$.

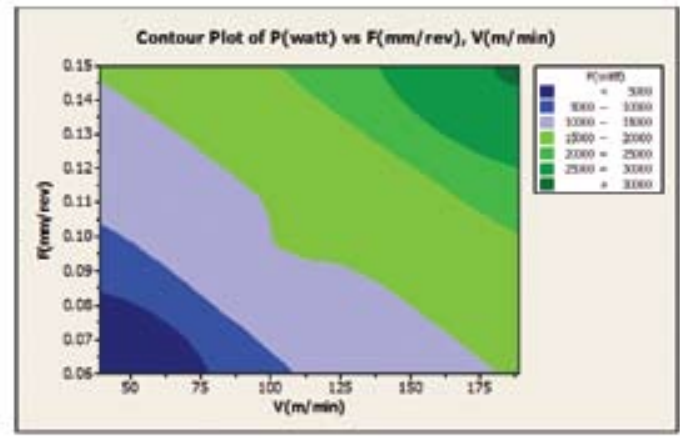

Figure 2a. Power counters in the cutting speed feed rate plane for depth of cut $0.2 \mathrm{~mm}$ and tool nose radius $0.4 \mathrm{~mm}$

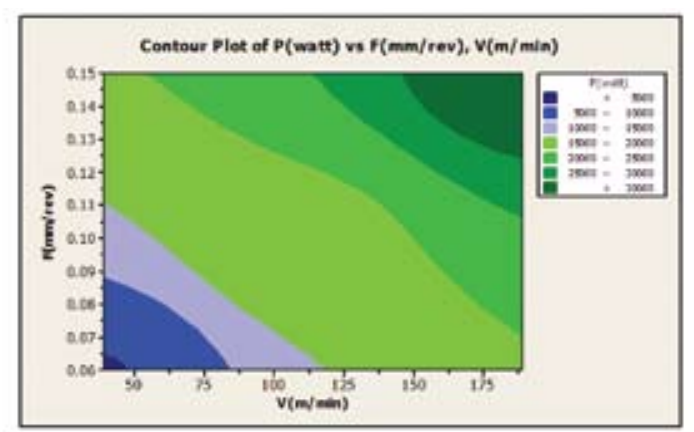

Figure 2b. Power counters in the cutting $\mathrm{v}$ feed rate plane for depth of cut $0.4 \mathrm{~mm}$ and tool nose radius $0.8 \mathrm{~mm}$

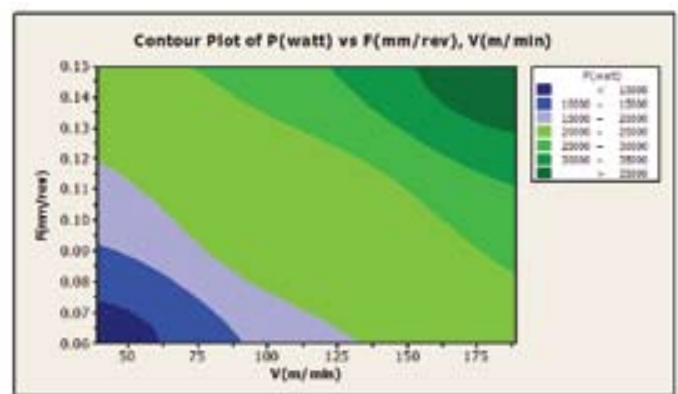

Figure 2c. Power counters in the cutting speed feed $0.6 \mathrm{~mm}$ and tool nose radius $1.2 \mathrm{~mm}$

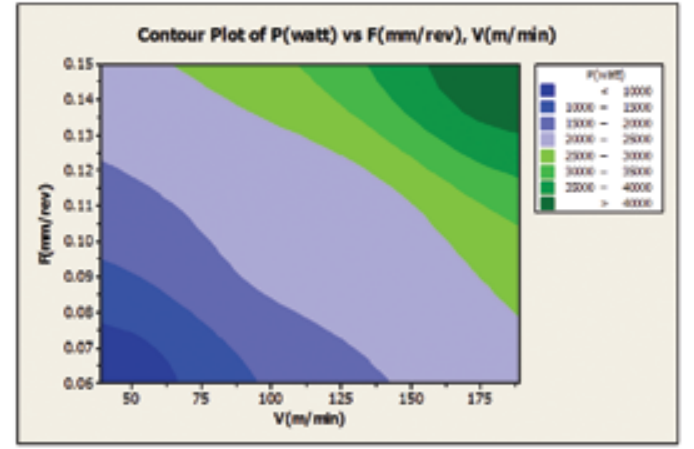

Figure 3a. Power counters in the cutting speed rate plane for depth of cut feed rate plane for depth of cut $0.2 \mathrm{~mm}$ and tool nose radius $0.4 \mathrm{~mm}$

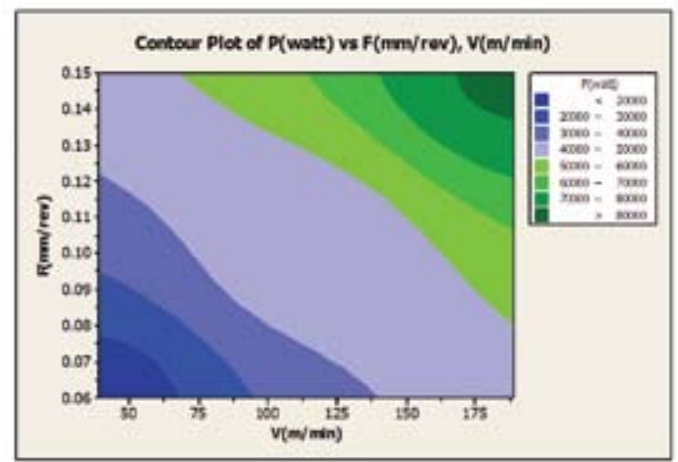

Figure 3b. Power counters in the cutting speed-feed rate plane for depth of cut $0.4 \mathrm{~mm}$ and tool nose radius $0.8 \mathrm{~mm}$

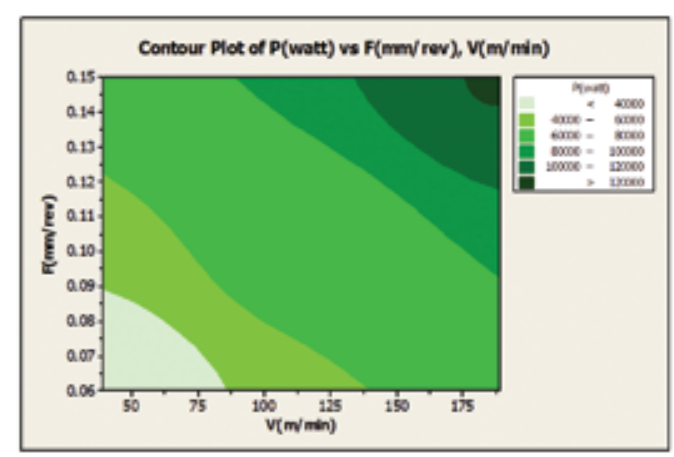

Figure 3c. Power counters in the cutting speed feed rate plane for depth of cut $0.6 \mathrm{~mm}$ and tool nose radius $1.2 \mathrm{~mm}$

It can be seen from figure $4 \mathrm{a}$ that the regression model is reasonably well fitted with the observed values. In addition, figure $4 \mathrm{~b}$ illustrates that there is no noticeable pattern or unusual structure. This implies that the proposed second order model is adequate to illustrate the pattern of the power.

The check of the normality assumptions of the data is then conducted; it can be seen in figure $4 \mathrm{c}$ that all the points on the normal plot come to close to forming a straight line. This implies that the data are fairly normal and there is a no deviation from the normality. This shows the effectiveness of the developed model. Notice that the residuals are falling on a straight line, which means that the errors are normally distributed.

Exponential model can be obtained for power by applying logarithmic transformation to eq. 2 as:

$\operatorname{Lnp}=\operatorname{lnc}+\mathrm{aln} v+b \ln f+c \ln d+d \ln r+\ln \varepsilon$ 
The transformed equation of power prediction in terms of metal cutting parameters (cutting speed, feed rate and depth of cut) and tool nose radius is as follows:

$\operatorname{Lnp}=7.32+1.08 * \mathrm{~V}+0.708 * \mathrm{~F}+0.882 * \mathrm{D}+0.31 * \mathrm{R}$

$\mathrm{P}=1510.204\left(\mathrm{v}^{\left.1.08 * \mathrm{~F}^{0.78} * \mathrm{D}^{0.882} * \mathrm{R}^{0.310}\right)}\right.$

The eq. 16 is derived from the eq. 12 , by substituting the coded values of cutting speed, feed rate, depth of cut and tool nose radius in terms of lnv, lnf, lnd and lnr. In eq. 16 cutting speed, feed rate, depth of cut and tool nose radius are expressed in logarithmic transformation. Since all the four parameters are under the same logarithmic scale, the factor with highest value of coefficient possesses the most dominating effect over the response.

The main and interaction effect plot for power has been shown in figure 5 and figure 6 . The plots show the variation of individual and interaction responses with the four parameters i.e. cutting speed, feed rate, depth of cut and tool nose radius separately. In the plots, $x$-axis shows the value of each parameter at three levels and y-axis the response values. Horizontal line in the plot shows the mean value of the response. Figure 5 shows the main effect plot for power showing the effect of cutting speed, feed rate, depth of cut and tool nose radius. The results show that decreasing cutting speed, feed rate, depth of cut and tool nose radius, there is continuous decrease in power consumption i.e. smaller values of cutting parameters and tool nose radius produces smaller power consumption and larger values of cutting parameters there is required larger power for machining EN-31 steel.

Interaction plot figure 6 shows the variation of power due to interaction between cutting speed and feed rate $\left(\mathrm{v}^{*} \mathrm{f}\right)$, feed rate and

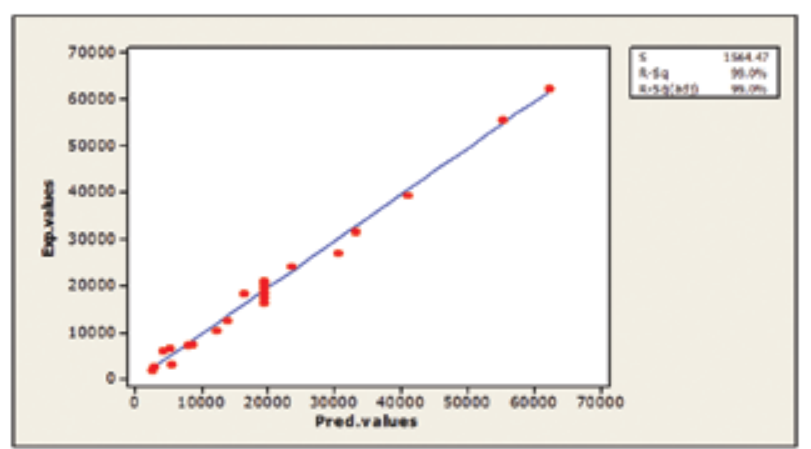

Figure 4a. Experimental vs. Predicted values

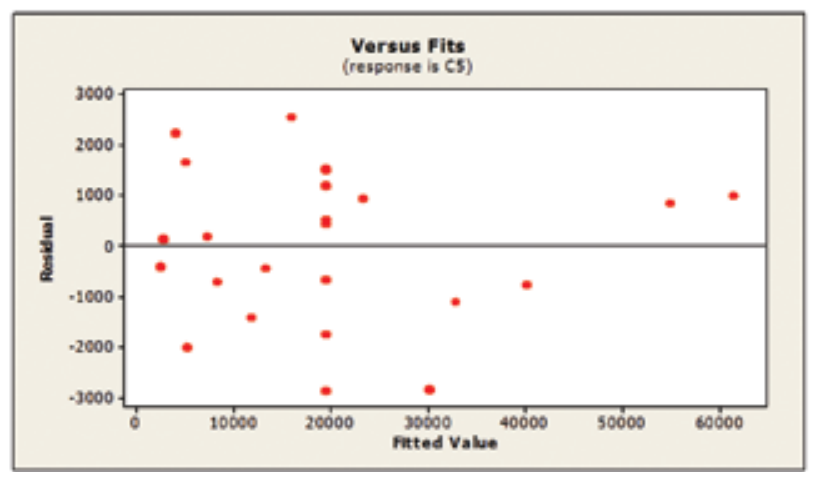

Figure 4b. Residual vs. fitted values

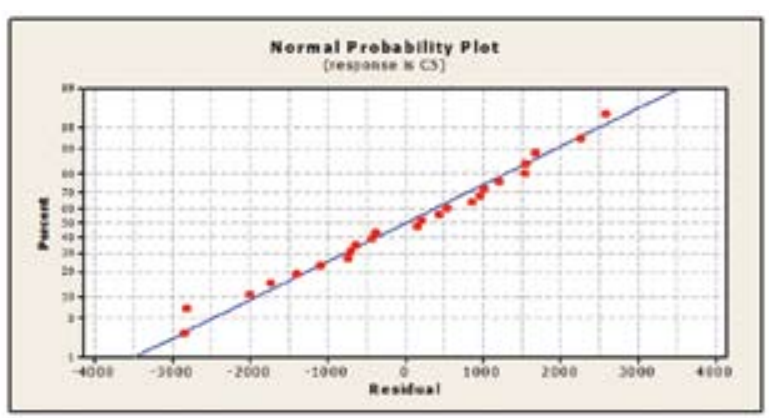

Figure 4c. Normal probability plot

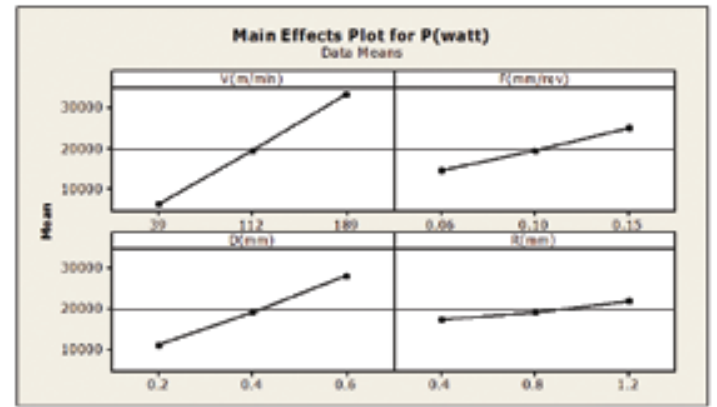

Figure 5. Main effect plot for $\mathrm{P}$ (watt)

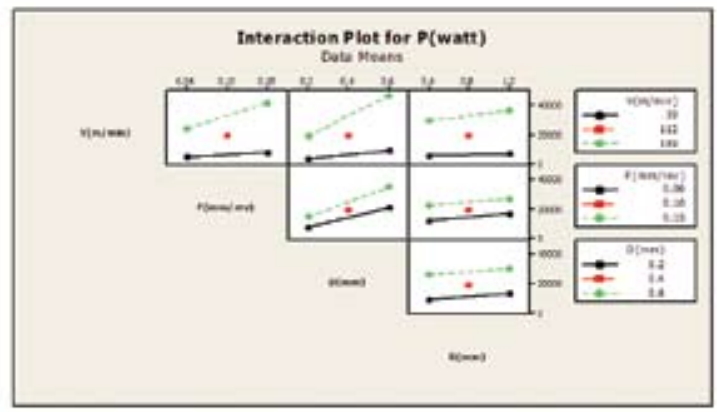

Figure 6. Interaction effect plot for Power (watt)

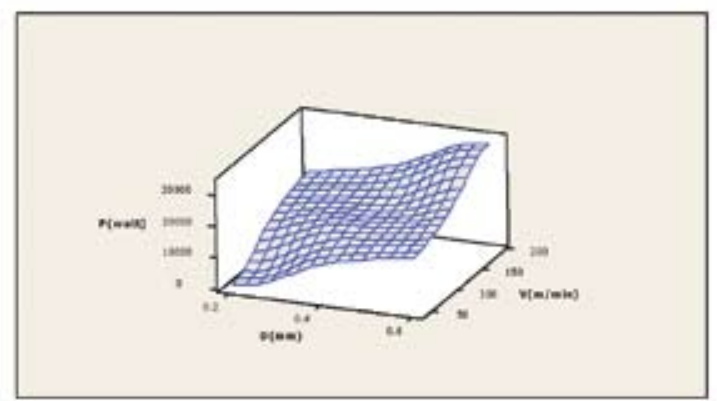

Figure 7a. Residual 3D plot of power when feed rate $0.06 \mathrm{~mm} / \mathrm{rev}$ and tool nose radius $0.4 \mathrm{~mm}$

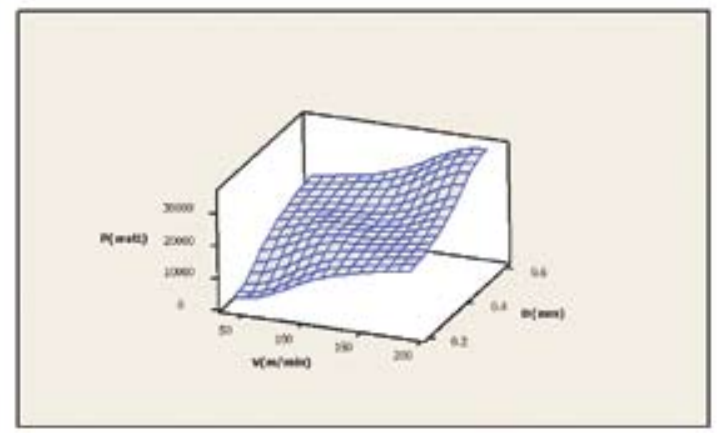

Figure 7b. 3D plot of power when feed rate $0.10 \mathrm{~mm} / \mathrm{rev}$ and tool nose radius $0.8 \mathrm{~mm}$ 


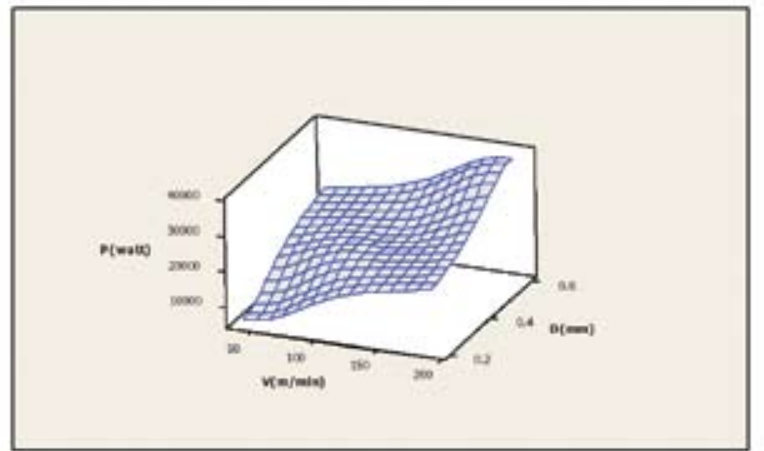

Figure 7c. 3D plot of power when feed rate $0.15 \mathrm{~mm} / \mathrm{rev}$ and tool nose radius $1.2 \mathrm{~mm}$

depth of cut $\left(f^{*} \mathrm{~d}\right)$ and cutting speed and depth of cut $\left(\mathrm{v}^{*} \mathrm{~d}\right)$. Figure 7 $(a, b, c)$ show the three dimensional plot for metal cutting power.

\section{Conclusion}

1) Response surface method is found to be a successful technique to perform trend analysis of power consumption in metal cutting with respect to various combinations of design variables (metal cutting speed, feed rate, depth of cut and tool nose radius).

2) The first order, second order and exponential models are found to be adequately representing metal cutting power with experimental results. Second order model is more precise than the first order model in predicting the power consumption during machining.

3) A logarithmic data transformation can be applied to convert the nonlinear form of equation into to the additive (linear) form. This is one of most popularly used data transformation technique in empirical model building.

4) The models developed in the research produces smaller errors and have satisfactory results. Therefore the proposed models can be used to predict the corresponding power consumption in metal cutting of EN-31 steel at different parameters in turning.

5) The smallest the values of the cutting speed, feed rate, depth of cut and tool nose radius, the lowest is the metal cutting power consumption. The counter plots show the safe zone for minimum power consumption. Thus, from the model equations and counter plots a designer can select the best combination of cutting variables for achieving optimum or minimum metal cutting power consumption during turning steel. This eventually may reduce the machining time, operator efforts, cost and save the cutting tools.

\section{Acknowledgement}

The authors would like to express their deep gratitude to the Department of Mechanical engineering of Aligarh Muslim University (AMU) for providing the laboratory facilities and financial support.

\section{References}

1. Trent E. M. Metal cutting, 2nd edition, Butterworth's \& Co. London, UK, limited, ISBN 0-408- 34-38, (1984).

2. Nagpal G. R. Machine Tool Engineering. Khanna Publishers, New Delhi, 68-71, (1986).

3. Kalpakjian S. Manufacturing Engineering and Technology, 4th Edition, Illinois Institute of technology; 545-548, (2000).

4. Montgomery D. C. Design and analysis of experiments, 3rd Edition, John Wiley and sons, New York, USA, pp.521-568, (1991).

5. Armarego E. J. A., Machining Performance prediction for Modern Manufacturing. In proc. 7th International Conference on Production and Precision Engineering and 4th International Conference on High Technology. Chiba Japan,(1994); K52.

6. W.U.S.M. Tool life testing by RSM (Part I and Part II) Transactions of ASME 86, 105-116, (1964).

7. Chou, Y. K., Song. H. Tool nose radius effects on finish hard turning, Journal of Materials Processing Technology, 148, 259-268, (2004).

8. Suresh P. V. S, Rao P. V, Deshmukh S. G. A genetic algorithm approach for optimization of surface roughness prediction model. International Journal of Machine Tool and Manufacture, 42, 675-680, (2002).

9. L. B. Abhang and M. Hameedullah. Development of a prediction model for surface roughness in finish turning of alloy steel. Int. Con. PSG. College Coimbatore, Narosa Publishing Housing New Delhi, India, 138-144, 21-23 Dec. (2009),

10. Anirban Bhattacharya, Santanu Das, P. Majumdar, Ajay Batish. Estimation of the effect of cutting parameters on surface finish and power consumption during high speed machining of AISI 1045 steel using Taguchi design and ANOVA. Prod. Eng. Res. Devel.3, 31-40, (2009).
11. Sood R., C. Guo and S. Malkin, Turning of hardened steels. Journal of Manufacturing Processes, 2(3):187-193, (2000).

12. Box G. E. P. and D. W. Behnken. Some new three level designs for the study of quantitative variables. Technometrics. 455-475, (1960).

13. Box. G. E. P. Statistics for experiments, John Wiley \& Sons Inc, USA, 38-46, (1978).

14. Fu H. J., R. E. DeVor and S. G. Kapoor. A Mechanistic Model for the prediction of the force System in face milling operations. J. Eng. for Industry 106, 81-88, (1984).

15. Noordin M.Y., Venkatesh V.C., Sharif S., Elting S., Abdullah A. Application of response surface methodology in describing the performance of coated carbide tools when turning AISI 1045 steel. Journal of Materials Processing Technology, 145: 46-58, (2004).

16. Aman A., Hari S., Pradeep Kumar, Manmohan S. Optimizing power consumption for CNC turned parts using response surface methodology and Taguchi technique- a comparative analysis. Journal of Materials Processing Technology, 200: 373-384, (2007).

17. Faleh A. Al-Sulaiman, M. A. Basser, A. K. Sheakh. Use of electrical power for online monitoring of tool condition. Journal of Materials Processing Technology, 20: 364-371, (2005).

18. Lin W. S., Lee B. Y. Modeling the surface roughness and cutting forces during turning. Journal of Materials Processing Technology, 108: 286-93, (2001)

19. Risbood K. A., Dixit U. S. and Sahasrabudhe A. D. Prediction of surface roughness and dimensional deviation by measuring cutting forces and vibration in turning process. Journal of Materials Processing Technology, 132: 203-14, (2003). 